\title{
Organisational support for nurses in acute care settings: a rapid evidence review
}

\author{
Alistair Hewison*1, Yvonne Sawbridge ${ }^{2}$ \\ ${ }^{1}$ Department of Nursing, University of Birmingham, Birmingham, United Kingdom \\ ${ }^{2}$ Health Services Management Centre, University of Birmingham, Birmingham, United Kingdom
}

Received: June 28, 2015

DOI: $10.5430 /$ ijh.v1n1p48
Accepted: August 5, 2015

Online Published: August 14, 2015

\begin{abstract}
Background: It is recognised that if high standards of patient care are to be provided, nursing staff need to be supported in managing the emotional component of their work.

Objective: The purpose of the review reported here was to examine the relevant literature to determine which approaches to staff support are effective in enabling nurses to manage the emotional content of their work. Design: A Rapid Evidence Assessment was conducted.

Methods: Rapid Evidence Assessment methods were used to identify and evaluate the relevant literature. Data sources: Peer reviewed journal papers retrieved as a result of a systematic literature search.

Results: A total of 1,869 papers were identified following two searches of electronic databases and 25 papers were included in the review. Thematic analysis identified three main themes in the papers: The importance of leadership-particularly emotionally intelligent leadership; the impact of aspects of the emotional content of nurses' work on their practice; and approaches to supporting staff.

Conclusions: The results confirmed the recognition of staff support as being crucial to patient care, and the role of leadership and a number of specific interventions including mindfulness, reflection and supervision were reported. However although there are many approaches to the provision of emotional support for nurses, there is little evidence to demonstrate their widespread implementation. It is accepted that emotion is central to nursing, yet how best to manage this in an organisational context is less clear.
\end{abstract}

Key Words: Emotional labour, Emotional intelligence, Staff support, Nursing, Leadership

\section{INTRODUCTION}

The importance of supporting and engaging staff who work in health care has been demonstrated ${ }^{[1]}$ and results in tangible benefits for patient care in terms of lower mortality and morbidity. ${ }^{[2,3]}$ Staff well-being is essential if high quality care is to be provided. ${ }^{[4-6]}$ However it has been recognised that if staff are to manage the emotional demands of their work, avoid burnout, and continue to provide care for patients they need to be supported in their workplace. ${ }^{[7-9]}$ In order to provide intimate, personal attention to patients, while recognizing their own personal limitations, nurses need to engage in coping mechanisms to balance these demands and protect themselves from burnout. ${ }^{[10]}$ It is important for caregivers to find regular ways to "recover" during the course of a working day, ${ }^{[11]}$ and a supportive team, ${ }^{[12,13]}$ with an effective ward leader ${ }^{[6]}$ have been found to be crucial in this respect.

\footnotetext{
*Correspondence: Alistair Hewison; Email: A.Hewison@bham.ac.uk; Address: Department of Nursing, University of Birmingham, Birmingham, B15 2TT, United Kingdom.
} 
Emotion is central to nursing care and its importance is recognised in the discipline, ${ }^{[14-16]}$ and it is now also being acknowledged more widely. ${ }^{[17]}$ Caring involves emotional labour, which is the management of feeling to create a publicly observable facial and bodily display ${ }^{[18]}$ which over time can exert a toll on staff resulting in distress if appropriate support is not available.

The provision of support for staff can take a number of forms, for example managers accepting that the gossip that goes on in "unmanaged spaces" serves a function in shielding staff from the stress of emotion work. ${ }^{[19]}$ More "formal" approaches such as the establishment of staff support groups have also been advocated, ${ }^{[9]}$ because the regular support of a group of colleagues who face similar situations can help staff speak out about difficult encounters and dilemmas. However, as Ballatt and Campling ${ }^{[9]}$ concede, staff support groups are rare outside mental health and hospice settings. Other important responses include managers recognizing and valuing employees' work and offering support. ${ }^{[20]}$ More recently attention has been focused on developing appropriate learning environments to support teams in delivering compassionate care. ${ }^{[21,22]}$

Mannion ${ }^{[23]}$ has argued that enabling compassionate care requires not only a focus on the needs of the patients, but also on those of the caregiver, yet the extent to which organisational systems and processes, such as those noted above, reflect this importance is less clear. In view of this it is important to examine how staff can be helped by their organisations to manage their emotional labour. The purpose of this review was to identify and examine literature which reported work which has investigated and explored the challenges of, and approaches to supporting nursing staff to enable them to manage the emotional component of their work. The aim was to discover which approaches had potential to be deployed to enable staff to better care for their patients.

\section{METHOD}

A Rapid Evidence Assessment (REA), sometimes also referred to as a "brief review", ${ }^{24]}$ was conducted to examine the existing evidence relating to the provision of staff support for nurses in practice. Evidence in this context is defined in broad terms in line with the exploratory nature of the review and so included the results of systematic reviews and a range of other studies. This was necessary to develop a comprehensive review of work that had been undertaken in this area that could inform policy. A REA is a tool developed from the systematic review method and involves comprehensive electronic searches of appropriate databases, internet sources and follow-up of cited references. ${ }^{[25]}$ The use of REA is increasing, driven in the main, by the need to engage policy makers,

Published by Sciedu Press healthcare professionals, and consumers in a timely manner to provide evidence-based recommendations for healthcare practices and policies. $^{[26]}$ A REA can be completed in a shorter period of time than a systematic review, from three weeks to six months for example, ${ }^{[27]}$ and the review reported here was conducted over three months. In order to do this some concessions were made, for example hand searching of journals and textbooks was not undertaken to the same extent as would be the case in a full systematic review, and the "grey" literature was not searched. The shortened timeframe for producing results, whilst useful in a rapidly changing practice environment to inform policy development, can increase the likelihood of locating papers that report positive results because of publication bias, that is the tendency for studies that find significant relationships between variables of interest to have a higher chance of acceptance in academic journals than studies that find no such relationships. ${ }^{[28]}$ However, the framework recommended by Davies ${ }^{[29]}$ below was adopted in order to reduce this risk:

- Search the electronic and print literature as comprehensively as possible within the constraints of the project timetable;

- Collate descriptive outlines of the available evidence on a topic;

- Critically appraise the evidence;

- Sift out studies of poor quality;

- Provide an overview of what the evidence is saying.

Although there is no standardised methodology for undertaking a rapid review, ${ }^{[26]}$ they have been conducted in a range of policy areas including housing, ${ }^{[30]}$ alcohol and criminal harm, ${ }^{[31]}$ international development, ${ }^{[32]}$ improving health literacy, ${ }^{[33]}$ end of life care, ${ }^{[34]}$ and in reviewing health improvement strategies. ${ }^{[35]}$ They provide timely information to inform practice, however they are not a quick fix, and there should be no compromise on the quality of searching, critical appraisal or analysis. The only concession made in REAs is on the comprehensiveness and sensitivity of searching in the time available. ${ }^{[28]}$ A REA is a means of delivering rigorous and comprehensive synthesis of the available evidence, in a timely manner to meet the needs of policy makers. ${ }^{[25]}$

There were two main aims of the REA reported here:

(1) To identify and examine literature which reported work which has investigated and explored the challenges of, and approaches to supporting nursing staff to enable them to manage the emotional component of their work;

(2) To examine wider organisational factors that contribute to the development of a supportive work environment for nurses. 
This generated a number of key words that were used in the search (see Figure 1). The overall process followed is summarised in Figure 2 below.

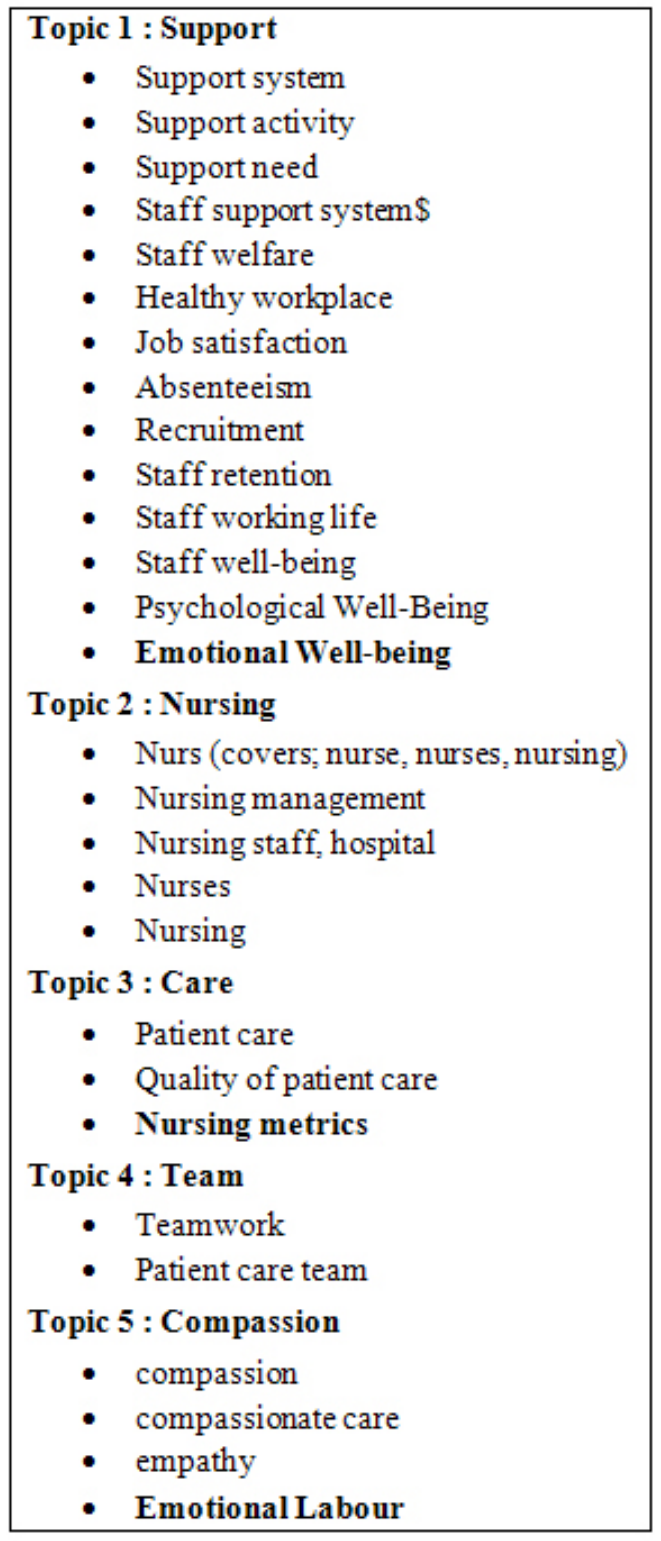

Figure 1. Key words: The key words above were used to search the relevant databases. The terms in bold text were added to the search strings following search 1 .

\section{Inclusion criteria}

Titles, abstracts and subsequently papers were included if they met the following inclusion criteria:

- Peer reviewed papers reporting primary research, systematic reviews and in-depth analyses drawing on research

- Papers that addressed the support of nursing staff in the conduct of the emotional component of their work
- Papers reporting work in a range of healthcare settings (in order to capture evidence of approaches focussed on nurses)

- Papers written in English

- Papers published from 2005 onwards

Exclusion criteria:

- Non-peer reviewed papers and "grey literature"

- Papers that examined staff support in non-health settings

- Papers written in languages other than English

- Papers focussed solely on workplace stress

- Papers reporting work in developing countries

- Opinion pieces and theoretical discussion papers

\section{RESUlts}

A total of 1,869 papers were identified following searches 1 and 2 (see Table 1 for details of databases searched). An additional search was conducted including the terms indicated in bold type in Figure 1. This was done to ensure the search was comprehensive as the yield from the first search was a little disappointing. Following review of the titles 172 were selected for retrieval of abstracts. Following review of the abstracts 36 papers were identified for appraisal. On detailed review of the papers a further 11 were excluded on the basis of relevance (e.g. conference abstracts only [1], not focussed on nursing [7], and repeats [3]). This resulted in a total of 25 papers being subjected to full review.

Table 1. The databases searched

\begin{tabular}{llll}
\hline Database & Search 1 & Search $\mathbf{2}$ & Notes \\
\hline HMIC & 0 & 13 & \\
Medline & 9 & 521 & \\
Embase & 8 & 355 & \\
Psychinfo & 1 & 72 & \\
ASSIA & 3 & 57 & Words “anywhere” \\
SC/SSCI & 37 & 488 & Topic only \\
Psycharticles & 8 & 173 & Title/ab/full text \\
Cinhal & 4 & 99 & All text \\
Total & 91 & 1,778 & 1,869 \\
\hline
\end{tabular}

Given the nature of the review it was not possible to apply a single set of quality criteria because of the varied nature of the papers retrieved that were relevant to its aims. In view of this the strengths and weaknesses of the papers were identified drawing on guidance provided by the Critical Skills Appraisal Programme ${ }^{[36]}$ and other sources. ${ }^{[24,37]}$

The papers were reviewed by the authors and the critical appraisal was summarised in a table which is too extensive to be included here. Thematic analysis of the papers was conducted following principles developed by Porter, ${ }^{[38]}$ which 
recommend a cyclical approach involving identification of patterns, consideration of variations and limitations, explanation of patterns and building explanations. The papers were read several times and codes assigned to key terms and phrases that reflected key findings reported in the papers in a manner similar to that used in grounded theory studies, ${ }^{[39,40]}$ these were subsequently grouped into categories, then themes reflecting the main areas addressed in the papers. ${ }^{[41]}$ This was an appropriate approach because of its flexibility and facility to integrate quantitative and qualitative findings. ${ }^{[42]}$ There were three main themes evident in the 25 papers. The importance of leadership-particularly emotionally intelligent leadership; the impact of aspects of the emotional content of nurses' work on their practice; and approaches to supporting staff. These are discussed under these broad headings and some general conclusions are then presented.

\subsection{Leadership and staff support}

A central theme found in the literature was the relationship of leadership to staff support. In particular the importance of emotional intelligence (EI) was found to be a crucial determinant of the level of support provided for staff. This was also manifested in "resonant" and "authentic leadership" approaches, which featured in the studies retrieved. These are examined below.

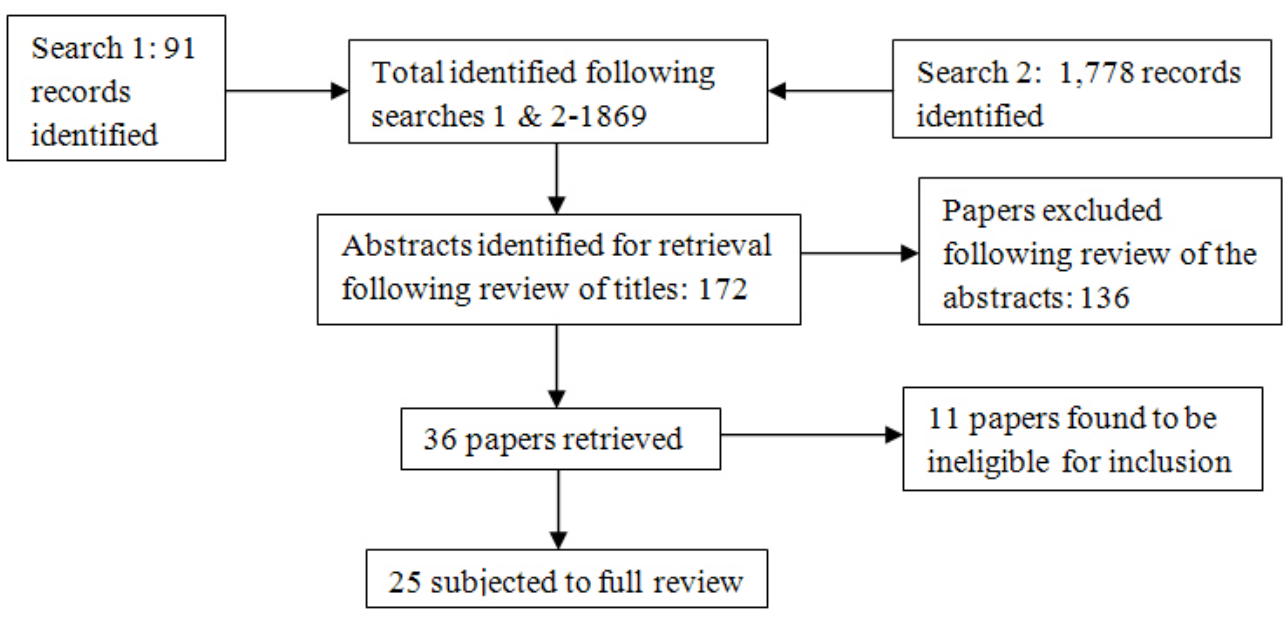

Figure 2. Flow chart of the review

In two literature based papers, one a systematic review ${ }^{[43]}$ and the other an integrative review ${ }^{[44]} \mathrm{EI}$ as a concept is examined and related to nursing leadership. It is concluded that the literature (16 papers) demonstrates that people with higher levels of EI have healthier, happier and more productive professional lives. ${ }^{[43]}$ In the review EI was defined as the ability to combine emotion with intelligence and use emotions as a support in problem solving and decision making, which helps people to live fulfilled lives, and is also used in a later paper. ${ }^{[45]}$ In an integrative synthesis of 18 papers a consistent theme reported in the papers was that emotionally intelligent nurse leadership has a positive impact on nurses' job performance and satisfaction. ${ }^{[4]}$ However, it is acknowledged that the research on EI is limited and requires further exploration in the context of nursing practice. ${ }^{[43]}$ It was concluded that emotionally intelligent leadership skills are vital in order to create a supportive environment and facilitate positive empowerment processes leading to staff well-being. ${ }^{[44]}$ In an empirical study designed to explore the relationship of emotionally intelligent leadership to nurse empowerment Lu- cas et al. ${ }^{[46]}$ conducted a predictive non-experimental survey involving 203 acute care nurses from two hospitals in Canada. EI in this context was defined as an individual's ability to manage themselves and their relationships effectively. ${ }^{[47]}$ This model was selected because it was competency based incorporating self-awareness, self-management, social awareness, and relationship management. ${ }^{[48]}$ Kanter's $^{[49]}$ theory of structural empowerment was also a central construct in the study. Although demonstrating weak claims for causality it is suggested that work-place organisational structures are foundational in shaping and enhancing work experience and employee work life (p970), furthermore it was found that highly emotionally intelligent nurse leaders may not be able to have a positive impact on staff empowerment if their span of control is too wide and prevents them interacting directly with their staff. ${ }^{[46]}$ This demonstrates that although emotionally intelligent leadership is central to effective staff support, it can be undermined by the organisational structure. Even if the leader demonstrates emotionally intelligent leadership, it will have limited impact if the structure prevents the leader 
engaging frequently and directly with staff.

The importance of leadership in supporting staff was addressed in three other papers. In a systematic review of 48 papers Pearson et al. ${ }^{[50]}$ identified 8 syntheses of evidence which demonstrated the elements of nurse leadership that foster a healthy work environment in healthcare. Those most pertinent to staff support were synthesis 3-leaders who exhibit characteristics associated with EI are likely to have a positive impact on staff, patient and organisational outcomes (p220); synthesis 7-leaders who exhibit the qualities and behaviours of being a motivator, being a supporter, being honest, listening and sharing information are likely to yield positive benefits for staff and patients (p221); and synthesis 8 -a supportive structure in an organisation can help people in leadership roles to support their staff (p221). Although it is acknowledged that the review is limited by the wide range of outcome measures used in the studies reviewed (p227), the meta analysis revealed that structures designed to empower leaders, who in turn empower their staff, can result in better outcomes leading to a healthier, more positive work environment. ${ }^{[50]}$ This is confirmed by Cummings et al. ${ }^{[51]}$ who investigated the mitigating effect of emotionally intelligent leadership on nurses during a period of organisational upheaval. Drawing on Goleman et al' ${ }^{[52]}$ notions of resonant leadership consisting of four leadership styles (visionary, coaching, affirmative, and democratic) which demonstrate high levels of EI, and dissonant leadership (pace setting and commanding styles) which do not. They analysed data collected as part of a survey of hospital characteristics. Thirteen questions from the survey were selected to reflect EI leadership competencies. In reporting the presence or absence of a range of work environment features, nurses provided information that identified the styles of their nursing leaders. Although based on self-report data and relying to a degree on "retro fitting" the dimensions of EI leadership to existing data, they found that the adverse impact of hospital re-structuring was reduced by resonant leadership, ${ }^{[51]}$ resonant leadership being a reflection of EI. Moreover by investing energy in relationships with nurses, resonant leaders positively affect the health and well-being of their nurses and ultimately the outcomes for patients. ${ }^{[51]}$ The findings from these papers emphasise the importance of leadership in creating a positive and supportive work environment. However, the range of terms and definitions employed suggest that different approaches are likely to be required in particular care settings to take account of the nature of the work, the team members, and wider context.

One literature based study ${ }^{[53]}$ explored the links between authentic leadership and healthy nursing work environments. In the study the components of healthy workplaces are itemised and discussed in detail. The findings from this component of the paper are used as the basis for a broad definition in which healthy work environments are seen to be supportive of the whole human being, are patient focused, and are joyful workplaces (p258). These in turn are reliant on authentic leaders, who have high levels of EI, conform to fact or speak the truth and are therefore worthy of trust, reliance or belief, thus enhancing work environment. ${ }^{[53]}$ This demonstrates the interrelationship of the concepts of authenticity, EI, and staff support. Twenty four papers were reviewed in all by Shirey ${ }^{[53]}$ (16 reporting research concerning healthy workplaces and 8 focussed on authentic leadership) and it is concluded that although the evidence demonstrates that healthy work environments produce superior outcomes for both staff nurses and patients, the empirical and theoretical base to support the link between authentic leadership and healthy work environments is limited at best. A research agenda is proposed as a means of addressing this deficit in the evidence base and it is acknowledged that although the role of leadership in serving as the "glue" that holds healthy workplaces together is strongly endorsed, the precise role of authentic leadership in this is less clear. It does however signal the interrelated nature of the factors that contribute to the development of an environment in which nurses feel supported and better able to care, whilst also signalling the need for further work in this area. A number of other key areas were identified in the literature.

\subsection{The impact of the emotional content of nurses' work} The recognition of the emotional nature of nurses' work and its impact on patient care if not managed appropriately has attracted considerable interest of late ${ }^{[17,23,54,55]}$ and a number of the papers identified in the REA report investigations of different aspects of this. For example social capital, defined as a resource that that can be available to both individuals and organisations, can have an effect on the levels of emotional exhaustion experienced by staff. Kowalski et $a l .{ }^{[56]}$ conducted a cross sectional retrospective study of 959 nurses working in four German hospitals. A range of biopsychosocial indicators were measured in the survey with the aim of determining the impact of a hospital's social capital on emotional exhaustion among nurses. This resource is comprised of relationships between people, collective values, and trust amongst members of an organisation. Thus it is a resource for helping people in the workplace to cope with stress and foster salutogenic potential. ${ }^{[56]}$ It was found that where social capital was rated as low by respondents they were more likely to be at risk of emotional exhaustion. Although acknowledging methodological limitations of self-report data, lack of generalisability, and difficulties in explaining the relationship of social capital to older, more 
experienced nurses, it indicates that approaches to reducing emotional burnout amongst nurses must take account of organisational factors such as relationships and staff support, as well as individual behavioural strategies. Another way of conceptualising the notion of a supportive organisation was examined by Grandey et al. ${ }^{[57]}$ They set out to examine if a climate of authenticity, defined as a shared perception about the extent that the unit values and accepts self-expression of emotions among members of the unit (p4), alleviated staff burnout. Their data suggest that the unit level climate can serve as a buffer against resource depletion amongst staff. It reduces the need for "surface acting" enabling staff to share their genuine emotions and thus feel more supported. Again, methodological caveats aside, which include concerns about the reliability of self-report data, reverse causality, and transferability of the findings to different organisational contexts, the central role of organisational relationships, and the importance of trust in supporting staff at work are reinforced. This followed earlier work which examined the relationship between emotional display rules negotiated at unit level, and emotional labour amongst nurses. ${ }^{[58]}$ The influence of work groups/teams on the extent to which nurses display emotion has an impact on levels of burnout and job satisfaction. If group norms allow for expression of emotions arising from "deep acting", then they are better able to manage their emotional labour.

Given the complex nature of workplace relationships, the dimensions of staff interaction that are felt to be supportive are important. In view of this the work by Chang et $a l .{ }^{[59]}$ to examine the relationship of nurse "agreeableness" and negative supervisor mood to nurses' intention to help colleagues, provides some useful insights. They contend that agreeableness should be considered a critical personality trait in nursing because of the prevalence of personal interactions involved in caring. Although it is argued that the trait of "agreeableness" is demonstrated by "abundant findings", the four sources cited in support of this assertion are all drawn from the psychological literature and the term is not commonly used in nursing, however the findings do point to the influential role that supervisors can have in encouraging nurses to help colleagues which in turn supports teamwork. This is confirmed by de Jonge et al. ${ }^{[60]}$ who had 826 returns to a cross sectional survey of 1,259 health care workers in elderly care facilities in the Netherlands and found that specific resources, including emotional support from colleagues and supervisors, provided self-regulatory mechanisms which enabled staff to deal with emotional job demands and reduce emotional exhaustion. Where health care workers reported that high levels of emotional support from colleagues and supervisors were available, emotional

Published by Sciedu Press job demands were positively associated with creativity and work motivation (p1467). Although this was not the case for all emotional job demands, and the study has some limitations with regard to self-report data, lack of detail concerning the number and role of nurses involved, and causal order of variables, it contributes to the emerging picture of the centrality of emotional support to maintaining staff health.

Organisational climate is an important resource for employees and has a direct impact on their health. ${ }^{[61]}$ In a discussion paper that draws on two earlier studies Smith et al. ${ }^{[62]}$ consider the challenge of managing emotions at work in the context of the need to create a safety culture in the English NHS. Summarising their own work ${ }^{[63-65]}$ and a range of other studies they argue there is substantive evidence to suggest patient and worker safety are linked through emotions at work. ${ }^{[62]}$ Indeed their overall conclusion serves as a useful summary of the collection of studies considered in this part of the REA and provides a link to the previous section on leadership:

The capacity of an organization and its leaders to listen and learn facilitates the recognition and effective management of emotions and is germane to the development of a culture that provides leadership for learning and promotes high standards of patient and worker safety and reduction of risk. The nature of the NHS workforce is changing and responsive systems need to be developed to ensure these standards are attained and sustained by emotionally intelligent leaders to ensure the delivery of quality care that is competent, compassionate and safe (p236). ${ }^{[61]}$

This recognition of the need to support staff in their emotional labour is explored further in the final section of the review. The third theme reflects the work that has focussed on the study of specific systems or approaches designed to provide emotional support.

\subsection{Approaches to supporting staff}

Consistent with the two main aims of the review a range of literature was examined which presented evidence concerning the effectiveness or impact of a number of approaches to the staff support on staff well-being and performance. These are examined below.

\subsubsection{Mindfulness interventions}

For example, the impact of Mindfulness (see Table 2) on emotional well-being of staff has been investigated. ${ }^{[66,67]}$ Both studies involved mindfulness training as an intervention, with one study employing a non-random pre and post test method to determine the impact of a telephonic Mindfulness-Based Stress Reduction Program (tMBSR). ${ }^{[66]}$ It was delivered by 
means of two full day "retreats", weekly telephone conference calls, and email support. Of the 72 nurses who participated in the programme 36 completed the survey at all three time points. It had a complex design which required participants to undertake and maintain a log of self-directed activities. It employed six scales to rate health status, feelings of serenity, and self compassion. It is presented as a pilot study and given its limitations (homogenous sample all female, all from one organisation, no control group), this is appropriate and a cautionary approach needs to be taken to the findings. It is suggested that blended delivery of tMBSR had a positive impact on self reported wellness measures and the results indicate that this approach to staff support may be worthy of further exploration.

Table 2. Four main elements characterise Mindfulness

1. It involves a receptive awareness and registration of inner
experiences (emotions, thoughts, intentions) and external events.
2 . Mindful information processing is pre-conceptual, that is in a
mindful state individuals are purely noticing what is happening
without evaluating, analysing or reflecting on it.
3. It is characterised by a present-oriented consciousness with a
focus on moment to moment experiences.
4. It is an inherent human capacity that varies in strength across
situations and individuals ${ }^{\text {[67] }}$.
Note. A self-directed practice for relaxing the body and calming the mind
through focussing on present moment awareness ${ }^{[66]}$.

In a similar investigation Hülsheger et al. ${ }^{[67]}$ undertook two studies to examine the impact of a mindfulness intervention on emotional exhaustion and job satisfaction. In the first, 568 questionnaires were distributed to staff in various organisations in the Netherlands and Belgium who were also required to complete twice daily diary entries over a period of 5 consecutive days. This may explain in part the low response rate of $38.6 \%$ ( 219 questionnaires returned) and prevented causal inferences being drawn. Also only $38.5 \%$ of the sample were nurses and so the findings have to be viewed in this context. It was found that mindfulness was positively related to job satisfaction, however whether or not it leads to a reduction in emotional exhaustion was not demonstrated. In the experimental field study from an original sample of 203, 102 participants, withdrew. A further 37 were excluded for a range of reasons (e.g. non-completion of diaries, insufficient meditation [a requirement of the programme]), resulting in a final sample of 64 (22 in the intervention group and 42 in the control group). Nurses were grouped with psychologists, salesmen and pharmacists making up just $3.1 \%$ of this small sample, so again the findings of this study need to be treated with extreme caution. However, the authors maintain it confirms the findings of their first study. It also reflects an interest in mindfulness as a means of helping staff manage their emotional labour, even if the findings are somewhat equivocal.

\subsubsection{Other forms of training}

Using training to help people understand and better manage stress was the focus of two studies reported by Siu et al. ${ }^{[68]}$ Following involvement in a training programme designed to enable the participants to learn about a range of stress related issues including its causes, relaxation techniques, the nature of resilience, positive psychology, and recovery, the impact of this intervention was evaluated using a number of scales for measuring psychological health. The first study involved health care workers and the second school teachers. Of the 1,034 health care workers recruited 817 completed both the pre and post test survey, of which $46 \%$ were registered nurses. The overall findings suggest a reduction in the potential for burnout and increased job satisfaction among the participants following the training. The second study is not discussed here because it involved teachers and so is not directly relevant to the emotional support of nurses in practice.

Other interventions with a more direct nursing focus which have been linked to staff support include reflection ${ }^{[69]}$ and clinical supervision. ${ }^{[70]}$ Horton-Deutsch and Sherwood ${ }^{[69]}$ examine reflection as a learning strategy for the development of emotionally competent nurse leaders. They identify seven levels of reflection, based on the work of Mezirow, ${ }^{[71,72]}$ and contend that emotional competence is a learned capability. Emotionally competent leaders are required because they can facilitate this emotional competence in others through active listening, questioning and reframing situations. Although reflection can be defined in a number of ways, and when conducted using a model is challenging, it is more than being thoughtful, it is a learning experience involving a rational and intuitive process leading to positive change for the individual. ${ }^{[69]}$ They call for more research in this area recognising there is little rigorous evidence of the outcomes from reflection, however, it would seem to have some potential for supporting nurses to develop emotional competence, if applied appropriately.

The use of clinical supervision as a means of supporting and developing the leadership capabilities of staff was investigated by Hyrkäs et al. ${ }^{[70]}$ In a two year study to investigate first line nursing managers' experiences of clinical supervision, data were collected in the form of empathy based stories which were subject to qualitative analysis to identify themes. From an original sample of 32, made up of 20 ward sisters and 12 nursing managers, the final sample after two years was 11 ( 7 ward sisters and 4 managers). Although a relatively limited data set it demonstrated that the 
respondents believed that clinical supervision had a positive impact with regard to developing their leadership and communication skills, increasing their self-knowledge and coping. Furthermore they felt clinical supervision could be used as a supportive measure for co-workers. This applied irrespective of whether the person being supervised had a positive or negative orientation to the process at the outset. This study was undertaken in Finland during a period of major organisational change, which limits its wider application, however the respondents' positive perspective on the process as a means of coping with such change suggests it has merit as part of a support system for nurses. This is confirmed by Wallbank ${ }^{[73]}$ who reports that a programme of Restorative Supervision has been delivered to more than 2,500 health professionals and is effective in reducing burnout, stress, and in increasing compassion satisfaction. The data presented in the paper are from a cross-sectional survey of 174 health visitors involved in the cascade of the restorative supervision model. Following six group supervision sessions the participants reported their levels of stress and burnout were lower and their level of compassion satisfaction increased. Restorative supervision is also identified as having the potential to enable staff to learn more about team functioning and support them in dealing with conflict. ${ }^{[73]}$ This approach is now being used more widely ${ }^{[74]}$ and may be beneficial for staff other than health visitors, and in particular for nurses working in acute care.

\subsubsection{Organisation wide interventions}

The final six papers in this category reported investigations of approaches developed to have a wider organisational impact, or advocate such an approach. For example Glass ${ }^{[7]}$ presents a strategic model for improving and sustaining hope, optimism and resilience. This is based on findings from a multi-site ethnographic study of 20 nurse academics in four countries. This involved participant observation, interviews and art-based reflections which revealed that the participants recognised the importance of resilience, hope and optimism in dealing with the nature of nursing and caring work. The strategic model is presented as a summary of the three critical components necessary for improving the workplaces of nurses and midwives. These are:

- Understanding the importance of the pervasive nature of, hope, optimism, and resilience;

- Cognitively reframing views on self in the workplace by drawing on psychological flexibility, adaptability, and EI;

- Grounding positive connections with friends and environment (p1251). ${ }^{[76]}$

However, she expresses concern that the model will have little impact if health and educational organisations do not

Published by Sciedu Press implement the changes necessary to promote healing in workplaces. In a study that moves beyond recommendations to the implementation of a specific model Dewar and Nolan ${ }^{[76]}$ worked with older people, staff and relatives to agree a definition of compassionate relationship centred care and identified strategies to promote it in an acute hospital. Drawing on the work of Lown et al. ${ }^{[77]}$ they used four essential characteristics of compassion as a starting point for reviewing the literature and conclude there is no model which articulates how it can be established and enabled to flourish in practice. ${ }^{[76]}$ This served as a basis for a study with 35 staff, 10 patients and 12 families to develop such a model. Using action research and appreciative inquiry they identified the components that make up a model of Compassionate Relationship Centred Care. These were, two key forms of relational knowledge - "knowing who I am and what matters to me" and "understanding how I feel". These were underpinned by seven attributes or the 7Cs of caring conversations namely being courageous, connecting emotionally, being curious, collaborating, considering other perspectives, compromising, and celebrating. Although involving only one ward the study does acknowledged the complex range of issues that need to be addressed if compassionate care is to be delivered, however it does not engage with the wider structural issues that need to be addressed if practice is to change. It seems staff are required to drive the change for example "the extent to which staff felt comfortable to challenge practice depended largely on the support they received from colleagues and senior staff which increased as the study progressed" (p1251), ${ }^{[76]}$ however it is not clear what happens if such support is not forthcoming. So although this work demonstrates a compassionate environment can be created on one ward with input from a researcher, the sustainability of the model more widely is less clear.

Two US papers report initiatives designed to improve the working environment of nurses. Meraviglia et al. ${ }^{[78]}$ worked with the Texas Nurses Association to devise 12 Nurse Friendly Hospital Criteria which were then introduced into 30 rural hospitals. The criteria included items such as control of nursing practice, safety of the work environment, nurse recognition, zero tolerance of nurse abuse, and middle management accountability. Each criterion had a set of operational indicators which needed to be met for the "Nurse Friendly" (NF) designation to be awarded. Visits from a team of experts supported the hospitals in developing strategies necessary to incorporate the criteria into policies and practices. Eighteen hospitals were successful in meeting all of the criteria and achieving NF status. The evaluation of the impact of the introduction of the NF criteria involved analysis of hospital demographics, staffing, and quality measures. 
A pre and post implementation survey of 1,149 nurses from the original 30 hospitals (pre) and 1,136 from 22 hospitals (post) was also undertaken. Overall it was found that nurses' appraisal of their work environment improved significantly as did the quality of patient care, and there was a slight improvement in nurse retention. This indicates that meeting the NF criteria had a positive impact on the nursing work environment. The recognition of the need to provide a healthy work environment if nurses are to be retained in post was also the starting point for a project conducted by Longo et $a l .{ }^{[79]}$ Using a "train the trainer" conference 120 health care workers were introduced to a number of topics including EI, relationship building, cultural competence, and generational differences. The intention was the delegates would then train staff in their own organisations in these areas. To evaluate the effectiveness of this approach a survey was conducted and thirty one evaluations were returned. The nurses reported that the programme had influenced their work behaviours, they were more self aware and had a greater understanding of the importance of relationships at work. However, $83.9 \%$ of the respondents made no attempt to deliver any training in their own workplace, as envisaged in the programme, and no new initiatives were developed. It is conceded that relying on such a "cascade" system, dependent on a small number of individuals, was perhaps a little unrealistic in terms of delivering major change and the variety of organisational systems may have made the transfer of learning difficult. However, the basic principle of involving all staff in the improvement of the working culture is reinforced. These two approaches ${ }^{[78,79]}$ have some similarities to the Magnet Hospital approach ${ }^{[80]}$ which has been subject to extensive research ${ }^{[81-87]}$ which has demonstrated the importance of having appropriate systems and procedures in place to support staff if high standards of patient care are to be delivered. This point is echoed in two review papers ${ }^{[88,89]}$ which conclude that if organisations care for staff they are more likely to be loyal and productive ${ }^{[88]}$ and nurses should feel they are supported, respected and know their contribution is valued, and that they have what they need to care for their patients. ${ }^{[89]}$ In a sense this brings the review full circle as the emerging evidence concerning the importance of staff engagement and support was used to set the context for the focus on staff support systems. ${ }^{[1-3]}$ The implications of the review are considered further below.

\section{Discussion}

Three broad categories of literature have been examined in this review: one highlighting the central role of effective leadership in supporting staff, particularly emotionally intelligent leadership; the second included material that reported the emotional impact of care on nurses; and the third was a collection of papers which reported and discussed particular approaches taken to supporting nurses in practice. The evidence presented in the range of papers included in the review, although not consistent in terms of the methodological approaches employed, indicates that the emotional content of care has an impact on staff, and if they are not supported in the management of its effects, the quality of patient care can be adversely affected. It also confirms there is no single effective method for supporting nursing staff in this complex area of their work. Although the nature of a REA means that it is unlikely to include all the relevant literature related to the search question and some papers may not have been identified, ${ }^{[28]}$ the material retrieved and considered in the review suggests that a reasonable balance between comprehensiveness and timeliness has been achieved. ${ }^{[25]}$ The papers included report empirical data, in the main, and provide some useful insights on the issues involved in supporting staff in caring roles which is an important international issue because a number of countries including England, New Zealand, the USA and the Netherlands have experienced organisational crises in healthcare resulting in failures in care ${ }^{[90]}$ which arise, in part from lack of staff support. For example, Martin and Dixon-Woods ${ }^{[91]}$ argue that if the lessons from a major hospital failure in England are to be learned then the seemingly straightforward solutions that characterise the problem as arising from poor performance in one hospital, or from "bad apple" staff need to be rejected, along with analyses that regard such occurrences as inevitable. There has also been recognition at policy level in England, that staff need support to care. In response the Department of Health has commissioned a programme of work from NHS Employers to develop tools and training for employers to promote the engagement and health and well-being of staff. ${ }^{[92]}$ The intention is that this will enhance their ability to provide compassionate care. However, as $\mathrm{Ham}^{[1]}$ observes if there were a silver bullet for securing high staff engagement, it would probably already have been found (p8). He goes on to conclude that if staff support and engagement are to be improved, leadership, empowerment of frontline staff, and appropriate governance and accountability will be needed. ${ }^{[1]}$ This presents considerable challenges because as Crawford et al. ${ }^{[93]}$ observe, in the increasingly target-driven, busy bureaucratic culture of health care where individual practitioners are intensively audited and monitored or told that their jobs hang in the balance, the very thing that health care traditionally aspires to-caring for people-may be severely compromised (p2). However, the evidence suggests that supporting staff is vital if they are to be able to continue to care for their patients. ${ }^{[21,22,94-97]}$ In short staff need to be emotionally supported, ${ }^{[6,7]}$ a pressing policy issue that 
needs to be addressed. Approaches such as the Schwartz Center Rounds ${ }^{[98,99]}$ and projects focussed on the creation of compassionate care environments ${ }^{[22,76]}$ are examples of organisational approaches being introduced to provide such support. However, further work is needed to explore how staff support can be developed in different organisations in a range of settings and more consideration given to the role of leadership in this process.

The insights provided by this REA indicate the broad areas of activity that need to be addressed in health care organisations. Whilst not providing definitive evidence for an overall solution to the challenge of supporting staff, it does signal that the combination of emotionally intelligent leadership with particular approaches to staff support which are congruent with the work setting, have the potential to reduce the emotional burden on staff and improve patient care. One of the purposes of an REA is to provide evidence-based recommendations for healthcare practices and policies, ${ }^{[26]}$ and the present review has highlighted three main areas that need attention in this respect.

\section{Conclusion}

Emotion is central to nursing care and its importance is acknowledged in the discipline, ${ }^{[14-16]}$ however, the extent to which organisational systems and processes reflect this importance is less clear. Also despite the utility of the concept in surfacing the labour involved in emotion work it is also, somewhat paradoxically, rendered invisible, is not managed, and the emotional dissonance caused by the constant suppression of powerful emotions can lead to burnout. ${ }^{[100]}$ The findings from this REA confirm this assessment and indicate that leadership of particular organisational approaches to staff support, have the potential to enable nurses to manage the emotional component of their work. The application of the findings and principles explored in this review needs to be appropriate to the setting, and further work to evaluate the impact of these approaches is required. The corpus of work in this area is somewhat diffuse, indicating a need for further investigation, particularly with regard to exploring the relationship between leadership and staff support.

\section{ACKNOWLEDGeMents}

We are grateful to Health Education West Midlands for funding this work and to Rachel Posaner for her help in conducting the literature search.

\section{REFERENCES}

[1] Ham C. Improving NHS Care by Engaging Staff and Devolving Decision Making. Report of the Review of Staff Engagement and Empowerment in the NHS. London, King's Fund. 2014

[2] West M, Dawson J. Employee Engagement and NHS Performance. London, The King's Fund. 2012.

[3] West M, Baker R, Dawson J, et al. Quality and Safety in the NHS: Evaluating progress, problems and promise. Lancaster, University of Lancaster, Lancaster. 2013. Available from: http://www. lancas ter.ac.uk/media/lancaster-university/content-asset s/documents/lums/cphr/quality-safety-nhs-e.pdf

[4] Davies S, Nolan M, Brown J, et al. Dignity on the ward: promoting excellence in care-Good practice in acute hospital care for older people. London, Help the Aged. 1999.

[5] Nolan MR, Brown J, Davbies S, et al. The Senses Framework: improving care for older people through a relationship centred approach. Sheffield: University of Sheffield; 2006.

[6] Maben J, Peccei R, Adams M, et al. Exploring the relationship between patients' experience of care and the influence of staff motivation, affect and wellbeing. London, Service Delivery and Organisation Programme, National Institute for Health Research. 2012.

[7] Maben J, Adams M, Peccei R, et al. 'Poppets and parcels': the links between staff experience of work and acutely ill older peoples' experience of hospital care. Int J Older People Nurs. 2012; 7(2): 83-94. PMid: 22531048. http://dx.doi .org/10.1111/j.1748-3743. $2012.00326 . x$

Published by Sciedu Press
[8] Heaslip V, Board M. Does nurses' vulnerability affect their ability to care? Br J Nurs. 2012; 21(15): 912-916. PMid: 22874859. http://dx.doi.org/10.12968/bjon.2012.21.15.912

[9] Ballatt J, Campling P. Intelligent Kindness-reforming the culture of healthcare. London: The Royal College of Psychiatrists; 2011.

[10] McQueen ACH. Emotional intelligence in nursing work. J Adv Nurs. 2004; 47(1): 101-108. PMid: 15186473. http://dx.doi.org/10. $1111 / j .1365-2648.2004 .03069 . x$

[11] Lilius JM. Recovery at work: understanding the restorative side of 'depleting' client interactions. Ac Mgt Rev. 2012; 37(4): 569-588.

[12] Horsburgh D, Ross J. Care and compassion: experiences of newly qualified staff nurses. J Clin Nurs. 2013; 22: 1124-132. PMid: 23480502. http://dx.doi.org/10.1111/jocn. 12141

[13] Patterson M, Nolan M, Rick J, et al. From metrics to meaning: culture change and quality of acute hospital care for older people. London, Service Delivery and Organisation Programme, National Institute for Health Research. 2012.

[14] Smith P. The Emotional Labour of Nursing Revisited. 2nd edn Houndmills: Palgrave; 2012.

[15] Bulmer Smith K, Profetto-McGrath J, Cummings GG. Emotional intelligence and nursing: an integrative review. Int J Nurs Stud. 2009; 46: 1624-1636. PMid: 19596323. http://dx.doi.org/10.1016 /j.ijnurstu.2009.05.024

[16] Bolton SC. Changing faces: nurses as emotional jugglers. Soc Heal \& Ill. 2001; 23(1): 85-100. http://dx.doi.org/10.1111/146 $7-9566.00242$ 
[17] Department of Health. Patients First and Foremost The Initial Government Response to the Report of the Mid Staffordshire NHS Foundation Trust Public Inquiry, London, Department of Health. 2013.

[18] Hochschild AR. The Managed heart. Berkeley: University of California Press; 1983. PMid: 6218886.

[19] Waddington K, Fletcher C. Gossip and emotion in nursing and healthcare organizations. J of Health Org and Mgt. 2005; 19(4/5): 378-394 PMid: 16206920. http://dx.doi.org/10.1108/14777260510 615404

[20] McFadzean F, McFadzean E. Riding the emotional roller-coaster. J of Health Org and Mgt. 2005; 19 (4/5): 318-339. PMid: 16206917 http://dx.doi.org/10.1108/14777260510615378

[21] Bridges J, Fuller A. Creating learning environments for compassionate care (CLECC): a programme to promote compassionate care by health and social care teams. Working Papers in Health Sciences. 2013; 1(5): 1-7.

[22] Bridges J, Fuller A. Creating learning environments for compassionate care: a programme to promote compassionate care by health and social care teams. Int J Older People Nurs. 2014; 10(1): 48-58. PMid: 24849082. http://dx.doi.org/10.1111/opn. 12055

[23] Mannion R. Enabling compassionate healthcare: perils, prospects and perspectives. Int J Heal Pol and Mgt. 2014; 2(3): 115-117. PMid: 24757687. http://dx.doi.org/10.15171/ijhpm.2014.34

[24] Abrami PC, Borokhovski E, Bernard RM, et al. Issues in conducting and disseminating brief reviews of evidence. Evi \& Pol. 2010; 6(3): 371-389. http://dx.doi.org/10.1332/174426410X524866

[25] Thomas J, Newman M, Oliver S. Rapid evidence assessments of research to inform social policy: taking stock and moving forward Evi \& Pol. 2013; 9(1): 5-27. http://dx.doi.org/10.1332/174 $426413 \times 662572$

[26] Watt A, Cameron A, Sturm L, et al. Rapid reviews versus full systematic reviews: an inventory of current methods and practice in health technology assessment. Int J Tech Assess in Heal Care. 2008; 24(2): 133-139. PMid: 18400114. http://dx.doi.org/10.1017 /S0266462308080185

[27] Ganann R, Ciliska D, Thomas H. Expediting systematic reviews: methods and implications of rapid reviews. Imp Sci. 2010; 5(56): 1-10. http://dx.doi.org/10.1186/1748-5908-5-56

[28] Davies P. What is needed from research synthesis from a policymaking perspective? In Popay, J. (Ed) Moving beyond effectiveness in evidence synthesis Methodological issues in the synthesis of diverse sources of evidence. London: National Institute for Health and Clinical Excellence; 2006. 97-103 p.

[29] Davies PT. Rapid evidence assessments: a tool for policy making? London: Government Social Research; 2004. Available from: www.gsr.gov.uk/news/rapid_evidence_assessments.asp

[30] Whitehead C, Monk S, Burgess G, et al. Rapid evidence review of the research literature on the impact of worsening affordability. Cambridge: University of Cambridge; 2008.

[31] Booth A, Meier P, Shapland J, et al. Alcohol pricing and criminal harm: a rapid evidence assessment of the published research literature. Sheffield: University of Sheffield; 2012. Available from: https://www.gov.uk/government/uploads/system/uploa ds/attachment_data/file/98138/rapid-evidence-asses sment.pdf. Accessed 20th June 2014.

[32] Department for International Development Infrastructure: Rapid Evidence Reviews. Evidence on Demand. UK. 2012. 248 p. http: //dx.doi.org/10.12774/eod_hd03.sep2012.anon

[33] D'Eath M, Barry MM, Sixsmith J. Rapid Evidence Review of Interventions for Improving Health Literacy. Stockholm: European Centre for Disease Prevention and Control; 2012.
[34] Parry R, Seymour J, Whittaker B, et al. Rapid evidence review: pathways focused on the dying phase in end of life care and their key components. Nottingham, Sue Ryder Care Centre for the Study of Supportive, Palliative and End of Life Care: University of Nottingham; 2013.

[35] Dixon-Woods M, McNicol S, Martin G. Ten challenges in improving quality in healthcare: lessons from the Health Foundation's programme evaluations and relevant literature. BMJ Qual and Safe. 2014; 21: 876-884. PMid: 22543475. http://dx.doi .org/10.11 36/bmjqs-2011-000760

[36] Available from: http://www. casp-uk.net/. accessed 25th May 2012.

[37] Long AF, Godfrey M. An evaluation tool to assess the quality of qualitative research studies. Int J Soc Res Meth. 2007; 7(2): 181-196. http://dx.doi.org/10.1080/1364557032000045302

[38] Porter S. Qualitative analysis. In: The Research Process in Nursing, 3rd edn (D.F.S. Cormack ed.). Oxford: Blackwell Science; 1996 330-340 p.

[39] Strauss A, Corbin J. Basics of Qualitative Research. London: Sage Publications; 1998.

[40] Charmaz K. Constructing Grounded Theory. London: Sage; 2006.

[41] Miles MB, Huberman AM. Qualitative Data Analysis, 2nd edn. Thousand Oaks: Sage Publications, CA; 1994.

[42] Dixon-Woods M, Agarwal S, Jones D, et al. Synthesising qualitative and quantitative evidence: a review of possible methods. J Heal Serv Res Pol. 2005; 10(1): 45-53. http://dx.doi.org/10.1258/135 5819052801804

[43] Akerjordet K, Severinsson E. Emotional intelligence: a review of the literature with specific focus on empirical and epistemological perspectives. J Clin Nurs. 2007; 16: 1405-1416. PMid: 17655529. http://dx.doi.org/10.1111/j.1365-2702.2006.01749.x

[44] Akerjordet K, Severinsson E. Emotionally intelligent leadership: a literature review. J Nurs Mgt. 2008; 16: 585-577. PMid: 18558927. http://dx.doi.org/10.1111/j.1365-2834.2008.00893.x

[45] Akerjordet K, Severinsson E. Emotional intelligence in mental health nurses talking about practice. Int $\mathrm{J}$ of Ment Heal Nurs. 2004; 13 : 164-170. PMid: 15361171. http://dx.doi.org/10.1111/j.1 440-0979.2004.0328.x

[46] Lucas V, Laschinger HK, Wong CA. The impact of emotional intelligent leadership on staff nurse empowerment: the moderating effect of span of control. J Nurs Mgt. 2008; 16: 964-973. PMid: 19094109. http://dx.doi.org/10.1111/j.1365-2834.2008.00856.x

[47] Goleman D. Emotional Intelligence. London: Bloomsbury; 1995.

[48] Goleman D. Working with Emotional Intelligence. New York: Bantam Books; 2001. PMid: 11346553.

[49] Kanter R. Men and Women of the Corporation. New York: Basic Books; 1993.

[50] Pearson A, Laschinger H, Porritt K, et al. Comprehensive systematic review of evidence on developing and sustaining nursing leadership that fosters a healthy work environment in healthcare. Int J Evi based Heal. 2007; S: 208-253.

[51] Cummings G, Haydik L, Estabrooks C. Mitigating the impact of hospital restructuring on nurses-the responsibility of emotionally intelligent leadership. Nurs Res. 2005; 54(1): 2-12. PMid: 15695934 http://dx.doi.org/10.1097/00006199-200501000-00002

[52] Goleman D, Boyatzis R, McKee A. The New Leaders: Transforming the Art of Leadership Into the Science of Results. London: Little Brown; 2002.

[53] Shirey MR. Authentic leaders creating healthy work environments for nursing practice. Am J Cri Care. 2006; 15: 256-267. PMid: 16632768. 
[54] Hayward RM, Tuckey MR. Emotions in uniform: How nurses regulate emotion at work via emotional boundaries. Hum Rel. 2011; 64(11): 1501-1523. http://dx.doi.org/10.1177/001872671 1419539

[55] Rankin B. Emotional intelligence: enhancing values-based practice and compassionate care in nursing. J of Adv Nurs. 2013; 69(12): 2717-2725. PMid: 23621353. http://dx.doi.org/10.1111/j an. 12161

[56] Kowalski C, Ommen O, Driller E, et al. Burnout in nurses - the relationship between social capital in hospitals and emotional exhaustion. J Clin Nurs. 2010; 19: 1654-1663. PMid: 20384668. http://dx.doi.org/10.1111/j.1365-2702.2009.02989.x

[57] Grandley A, Chuen F, Groth SM, et al. Free to be you and me: A climate of authenticity alleviates burnout from emotional labour. J Occ HealPsy. 2012; 17(1): 1-14.

[58] Diefendorf JM, Erickson RJ, Grandey AA, et al. Emotional display rules as work unit norms: a multilevel analysis of emotional labour among nurses. J Occ Heal Psy. 2011; 16(2): 170-186. PMid: 21244168. http://dx.doi.org/10.1037/a0021725

[59] Chang H, Teng C, Chu T, et al. Impact of nurse agreeableness and negative mood of nursing supervisors on intention to help colleagues. J Adv Nurs. 2011; 68(3): 636-646. PMid: 21740460. http://dx.doi.org/10.1111/j.1365-2648.2011.05776.x

[60] De Jonge J, Le Blanc PM, Peeters MCV, et al. Emotional job demands and the role of matching job resources: A cross sectional survey study among health care workers. Int J Nurs Studies. 45: 1460-1469. PMid: 18221742. http://dx.doi.org/10.1016/j .ijnurstu.2007.11.002

[61] Drach-Zahavy A. How does service workers' behaviour affect their health? Service climate as a moderator in the service-behavior relationships. J Occ Heal Psy. 2010; 15(2): 105-119. PMid: 20364909. http://dx.doi.org/10.1037/a0018573

[62] Smith P, Pearson PH, Ross F. Emotions at work: what is the link to patient and staff safety? Implications for nurse managers in the NHS. J Nurs Mgt. 2009; 17: 230-237. PMid: 19416427. http://dx.doi.org/10.1111/j.1365-2834.2009.00980.x

[63] Smith P. The Emotional Labour of Nursing: How nurses care. Basingstoke: Macmillan; 1992.

[64] Ross F, Christian S, Clayton J, et al. Professionals' Experience of Governance and Incentives: meeting the needs of individuals with complex needs in primary care. London, National Institute for Health research, Service Delivery and Organisation Programme. 2008.

[65] Pearson PH, Steven A, Howe A. Patient Safety in Health care Professional Education: Examining the learning experience. London, Department of Health, 2008.

[66] Bazarko D, Cate RA, Azocar F, et al. The impact of an innovative mindfulness-based stress reduction program on the health and wellbeing of nurses employed in a corporate setting. J Work Beha Heal. 2013; 28: 107-133. PMid: 23667348. http://dx. doi.org/10.10 $80 / 15555240.2013 .779518$

[67] Hülsheger UR, Alberts HJ, Feinholdt A, et al. Benefits of mindfulness at work: the role of mindfulness in emotion regulation, emotional exhaustion, and job satisfaction. J App Psy. 2013; 98(2): 210-325. http://dx.doi.org/10.1037/a0031313

[68] Siu OL, Cooper CL, Phillips DR. Intervention studies on enhancing work well-being, reducing burnout, and improving recovery experiences among Hong Kong health care workers and teachers. Int $\mathrm{J}$ Stress Mgt. 2014; 21(1): 69-84. http://dx.doi.org/10.1037/a 0033291

[69] Horton-Deutsch S, Sherwood G. Reflection: an educational strategy to develop emotionally competent nurse leaders. J Nurs Mgt. 2008;
16: 946-954. PMid: 19094107. http://dx.doi.org/10.1111/j $.1365-2834.2008 .00957 . x$

[70] Hyrkäs K, Appelqvist-Schmidlechner K, Kivimäki K. First-line managers' views of the long-term effects of clinical supervision: how does clinical supervision support and develop leadership in health care? J Nurs Mgt. 2005; 13: 209-220. PMid: 1581983. http://dx.doi.org/10.1111/j.1365-2834.2004.00522.x

[71] Mezirow J. A critical theory of adult learning and education. Ad Edu. 1981; 32: 3-24. http://dx.doi.org/10.1177/0741713681032 00101

[72] Mezirow J. Transformative Dimensions of Adult Learning. San Frnacissco: Jossey-Bass; 1991.

[73] Wallbank S. Maintaining professional resilience through group restorative supervision. Comm Practit. 2013; 86(8): 26-28.

[74] Bigwood P. Using Restorative Supervision to Improve Clinical Practice and Safeguarding Decisions. London: Department of Health; 2013.

[75] Glass N. An investigation of nurses' and midwives' academic/clinical workplaces. Hol Nurs Prac. 2009; 23(3): 158-170. PMid: 19411995. http://dx . doi .org/10.1097/HNP. Ob013e3181a056c4

[76] Dewar B, Nolan M. Caring about caring: Developing a model to implement compassionate relationship centred care in an older people care setting. Int J Nurs Stud. 2013; 50: 1247-1258. PMid: 23427893. http://dx.doi.org/10.1016/j.ijnurstu.2013.01.008

[77] Lown B, Rosen A, Martilla JJ. An agenda for improving compassionate care: a survey shows about half patients say such care is missing. Heal Aff. 2011; 30(9): 1772-1595. PMid: 21900669. http://dx.doi.org/10.1377/hlthaff. 2011.0539

[78] Meraviglia M, Grobe SJ, Tabone S, et al. Creating a positive work environment-implementation of the Nurse-Friendly hospital criteria. J Nurs Adm. 2009; 39(2): 64-70. PMid: 19190422. http: //dx.doi.org/10.1097/NNA.0b013e318195a82b

[79] Longo J, Dean A, Norriss SD, et al. It starts with a conversation: A community approach to creating healthy work environments. J Cont Edu Nurs. 2011; 42(1): 27-35. PMid: 20839660. http://dx.doi.org/10.3928/00220124-20100901-03

[80] Available from: http://www.nursecredentialing.org/mag net . aspx. accessed 22nd July 2015.

[81] Aiken LH. The Magnet Nursing Services Recognition Program: A Comparison of Two Groups of Magnet Hospitals. Am J Nurs. 2000; 100(3): 26-36. http://dx.doi.org/10.1097/0000044 6-200003000-00040

[82] Aiken LH, Buchan J, Ball J, et al. Transformative impact of Magnet designation: England Case Study. J Clin Nurs. 2008; 17(24): 3330-3337. PMid: 19146592. http://dx.doi.org/10.1111/j $.1365-2702.2008 .02640 . x$

[83] Brady-Schwartz DC. Further Evidence on the Magnet Recognition Program: Implications for Nursing Leaders. J Nurs Admin. 2005; 35(9): 397-403. http://dx.doi.org/10.1097/00005110-200 509000-00009

[84] Drenkard K. The Business Case for Magnet $®$. J Nurs Admin. 2000; 40(6): 263-271. PMid: 20502195. http://dx.doi.org/10.1097 /NNA. Ob013e3181dfofd6

[85] Spence Laschinger HK, Almost J, Tuer-Hodes D. Workplace Empowerment and Magnet Hospital Characteristics: Making the Link. J Nurs Admin. 2003; 33(7/8): 410-422. http://dx. doi .org/10. 1097/00005110-200307000-00011

[86] Kelly LA, McHugh MD, Aiken LH. Nurse Outcomes in Magnet $\AA$ and Non-Magnet Hospitals. J Nurs Admin. 2011; 41(10): 428-433. PMid: 21934430. http://dx.doi.org/10.1097/NNA.0b013e3 1822eddbc 
[87] Upenieks VA. The Interrelationship of Organizational Characteristics of Magnet Hospitals, Nursing Leadership, and Nursing Job Satisfaction. Heal Care Man. 2003; 22(2): 83-98. http://dx.doi.org/1 $0.1097 / 00126450-200304000-00002$

[88] Henry LS, Henry JD. Using a strengths-based approach to build caring work environments. Am Ass Occ Heal Nurs J. 2007; 55(12): 501-503. http://dx.doi.org/10.1177/216507990705501204

[89] Bloniasz ER. Caring for the caretaker: A nursing process approach. Creative Nurs. 2011; 17(1): 12-15. http://dx.doi .org/10.1891 /1078-4535.17.1.12

[90] Dixon-Woods M, Baker R, Charles K, et al. Culture and behaviour in the English National Health Service: overview of lessons from a large multimethod study. BMJ Qual \& Safe. 2013; 0: 1-10. http://dx.doi.org/10.1136/bmjqs-2013-001947

[91] Martin GP, Dixon-Woods M. After Mid Staffordshire: from acknowledgement, through learning, to improvement. BMJ Qual \& Safe. 2014; 23: 706-708. PMid: 25038039. http://dx.doi .org/10.11 36/bmjqs-2014-003359

[92] Department of Health Hard Truths The Journey to Putting Patients First Volume One of the Government Response to the Mid Staffordshire NHS Foundation Trust Public Inquiry. London, Department of Health. 2014.

[93] Crawford P, Gilbert P, Gilbert G, et al. The language of compassion. Taiwan Int ESP J. 2011; 3(1): 1-16.
[94] Bridges J, Nicholson C, Maben J, et al. Capacity for care: metaethnography of acute care nurses' experiences. J Adv Nurs. 2013; 69(4): 760-772. PMid: 23163719. http://dx.doi.org/10.1111 /jan. 12050

[95] Karimi L, Leggat SG, Donohue L, et al. Emotional rescue: the role of emotional intelligence and emotional labour on well-being and jobstress among community nurses. J Adv Nurs. 2014; 70(1): 176-186. PMid: 23763612. http://dx.doi.org/10.1111/jan.12185

[96] National Institute for Health Care Excellence (NICE) NICE Public Health Guidance 22: Promoting Mental Wellbeing at Work guidance. Available from: nice.org.uk/ph22. 2009.

[97] Mastracci SE, Guy ME, Newman MA. Emotional Labor and Crisis Response-working on the razor's edge. New York: M.E. Sharp; 2012.

[98] Lown B, Manning C. The Schwartz Center Rounds: Evaluation of an interdisciplinary approach to enhancing patient-centered communication, teamwork and provider support. Aca Med. 2010; 85(6): 1073-1081. PMid: 20505412. http://dx.doi.org/10.1097/A CM. Ob013e3181dbf 741

[99] Goodrich J. Supporting hospital staff to provide compassionate care: Do Schwartz Center Rounds work in English hospitals? J Royal Soc Med. 2012; 105(3): 117-122. PMid: 22434811. http: //dx.doi.org/10.1258/jrsm.2011.110183

[100] Gray B, Smith P. Emotional labour and the clinical settings of nursing care: the perspectives of nurses in East London. Nurs Edu Prac. 2009; 9(4): 253-261. PMid: 18842462. http://dx.doi.org/10. 1016/j.nepr.2008.08.009 